\title{
Erratum to: Visualization of osseointegration of maxilla and mandible dental implants
}

\author{
Joerg Meyer - Cherilyn G. Sheets • \\ James C. Earthman
}

Published online: 7 April 2015

(C) CARS 2015

Erratum to: Int J CARS (2010) 5:69-76

DOI 10.1007/s11548-009-0382-2

Unfortunately, two author names were omitted in the original version of the article. The missing authors and their affiliations are given below:

C. G. Sheets

Newport Coast Oral Facial Institute, Newport Beach,

CA, USA

J. C. Earthman

Chemical Engineering and Materials Science Department,

University of California, Irvine, Irvine, CA, USA

The online version of the original article can be found under doi:10.1007/s11548-009-0382-2.

J. Meyer ( $\square)$

University of California, Irvine, Irvine, CA, USA

e-mail: jmeyer@uci.edu

C. G. Sheets

Newport Coast Oral Facial Institute, Newport Beach, CA, USA

J. C. Earthman

Chemical Engineering and Materials Science Department,

University of California, Irvine, Irvine, CA, USA 